\title{
Tricuspid annuloplasty concomitant with mitral valve surgery: Effects on right ventricular remodeling
}

\author{
Philippe B. Bertrand, MD, MSc, ${ }^{\text {a,b }}$ Gille Koppers, MSc, ${ }^{b}$ Frederik H. Verbrugge, MD, ${ }^{\text {a,b }}$ \\ Wilfried Mullens, MD, PhD, ${ }^{\mathrm{a}, \mathrm{b}}$ Pieter Vandervoort, $\mathrm{MD},{ }^{\mathrm{a}, \mathrm{b}}$ Robert Dion, $\mathrm{MD}, \mathrm{PhD},{ }^{\mathrm{c}}$ and \\ David Verhaert, $\mathrm{MD}^{\mathrm{a}}$
}

\begin{abstract}
Objectives: Tricuspid valve annuloplasty (TVP) has been advocated concomitantly with left-sided cardiac surgery in case of more than moderate tricuspid regurgitation (TR) or tricuspid annular dilation (TAD) (diameter $>40 \mathrm{~mm}$ or $21 \mathrm{~mm} / \mathrm{m}^{2}$ ) even in the absence of significant TR. Data on postoperative right ventricular (RV) remodeling are lacking in such patients.
\end{abstract}

\begin{abstract}
Methods: Preoperative and postoperative echocardiography data from 45 consecutive TVP procedures, performed in mitral valve surgery in a single tertiary center, were retrospectively analyzed and compared with a propensity-matched control group of 33 procedures without concomitant TVP. RV function and geometry was analyzed by measuring RV size, fractional area change, and end-diastolic sphericity index (RVSI = longaxis length/short-axis width) and compared at baseline versus follow-up.
\end{abstract}

\begin{abstract}
Results: At a mean follow-up of 5 months, a favorable change in RV geometry was observed in TVP patients (RVSI increased from $1.99 \pm 0.33$ to $2.21 \pm 0.42 ; P=.001$ ), whereas the opposite was observed in the control group (RVSI decreased from $2.34 \pm 0.52$ to $2.17 \pm 0.13 ; P=.05$ ). Only in control patients, indexed RV enddiastolic area increased significantly $(P=.003)$. In TVP patients, when comparing patients with baseline more than moderate TR $(\mathrm{n}=13)$ to patients with isolated TAD $(\mathrm{n}=32)$, there was a significant decrease in RV end-diastolic area only in the group with more than moderate TR (from $12.9 \pm 3.5 \mathrm{~cm}^{2} / \mathrm{m}^{2}$ to $10.3 \pm 1.9$ $\left.\mathrm{cm}^{2} / \mathrm{m}^{2} ; P=.009\right)$.
\end{abstract}

Conclusions: Adding TVP to mitral valve surgery in patients with more than moderate TR or TAD leads to favorable changes in RV geometry and prevents postoperative RV dilation. This is most pronounced in patients with more than moderate TR at baseline. (J Thorac Cardiovasc Surg 2014;147:1256-64)

De novo or progressive tricuspid regurgitation (TR) after successful left-sided heart surgery is commonly observed and associated with increased morbidity and mortality. ${ }^{1-3}$ Therefore, tricuspid valve annuloplasty (TVP) has been advocated to be performed concomitantly in case of more than moderate TR (TR $>2+$ ) and, more recently, also in case of tricuspid annular dilation (TAD, defined as a tricuspid annular diameter $>40 \mathrm{~mm}$ or $21 \mathrm{~mm} / \mathrm{m}^{2}$ ), irrespectively of TR. ${ }^{4,5}$ The rationale for performing TVP, even in patients with TAD but without significant TR (TR $\leq 2+$ ), relies on evidence that TAD is an ongoing disease process that over time often leads to severe functional TR. ${ }^{6}$ Although the effect of mitral valve surgery on left

From the Department of Cardiology, ${ }^{\text {a } Z i e k e n h u i s ~ O o s t-L i m b u r g, ~ G e n k, ~ B e l g i u m ; ~ t h e ~}$ Faculty of Medicine and Life Sciences, ${ }^{b}$ Hasselt University, Hasselt, Belgium; and the Department of Cardiovascular Surgery, ${ }^{c}$ Ziekenhuis Oost-Limburg, Genk, Belgium.

Disclosures: R.D. received consulting fees from Edwards Lifesciences, Johnson \& Johnson, Sorin, Medtronic, and St Jude Medical. All other authors have nothing to disclosure with regard to commercial support.

Received for publication Feb 22, 2013; revisions received April 8, 2013; accepted for publication May 2, 2013; available ahead of print July 1, 2013.

Address for reprints: Philippe B. Bertrand, MD, MSc, Department of Cardiology, Ziekenhuis Oost-Limburg, Schiepse Bos 6, 3600 Genk, Belgium (E-mail: philippe. bertrand@zol.be).

0022-5223/\$36.00

Copyright $(2) 2014$ by The American Association for Thoracic Surgery

http://dx.doi.org/10.1016/j.jtcvs.2013.05.007 ventricular (LV) geometry and function in patients with severe mitral regurgitation (MR) has been extensively studied, ${ }^{7-13}$ data on right ventricular (RV) geometry and function changes in response to TVP are surprisingly scarce. Although results have shown that mitral valve repair (MVP) induces reverse LV remodeling in a gradual and time-dependent fashion, it is not known whether TVP has similar beneficial effects on RV shape and function. Furthermore, it is not known whether the effects of TVP are different for patients with severe coexistent TR compared with those in whom mere TAD was the reason to intervene on the tricuspid valve.

Therefore, the objectives of this study were as follows: (1) to determine the differential effects on RV size, geometry, and function of TVP performed because of severe TR versus TAD without significant TR in patients scheduled for mitral valve surgery and (2) to compare the echocardiography data of this population with data from a propensitymatched cohort of patients undergoing similar procedures without TVP.

\section{METHODS}

\section{Study Population}

Figure 1 summarizes the study flow chart. Between July 2007 and December 2011, 316 mitral valve procedures of any kind were performed at 


$$
\begin{aligned}
& \text { Abbreviations and Acronyms } \\
& \begin{aligned}
\text { LV } & =\text { left ventricular } \\
\text { MR } & =\text { mitral regurgitation } \\
\text { MVP } & =\text { mitral valve repair } \\
\text { MVR } & =\text { mitral valve replacement } \\
\text { RV } & =\text { right ventricular } \\
\text { RVFAC } & =\text { right ventricular fractional area change } \\
\text { RVSI } & =\text { right ventricular sphericity index } \\
\text { TAD } & =\text { tricuspid annular dilation } \\
\text { TR } & =\text { tricuspid regurgitation } \\
\text { TVP } & =\text { tricuspid valve annuloplasty }
\end{aligned}
\end{aligned}
$$

Ziekenhuis Oost-Limburg (Genk, Belgium). These comprised mitral repair (MVP) or replacement (MVR) procedures in all patients, with a proportion of patients receiving concomitant coronary artery bypass grafting and/or concomitant aortic valve surgery. Concomitant TVP was systematically performed in 137 patients, when more than moderate TR (TR $>2$, ie, color Doppler jet area/atrial area $>20 \%{ }^{14}$ ) and/or TAD (tricuspid annular diameter $>40 \mathrm{~mm}$ or $>21 \mathrm{~mm} / \mathrm{m}^{2}$ ) was present. Only patients with complete preoperative and postoperative (3-6 months) echocardiography data and examinations performed at our center were included in the analysis. The TVP population thus consisted of 45 consecutive patients who underwent TVP together with left-sided heart surgery. There were no patients with structural (organic) tricuspid valve disease in the study population. From the remaining 53 patients undergoing mitral valve surgery without concomitant TVP, we recruited a control population of 33 patients by using propensity matching for age, gender, LV ejection fraction, LV enddiastolic volume, and cardiopulmonary bypass time. The study was approved by the locally appointed ethics committee, which waived the need for individual consent owing to the retrospective and observational nature of the study.

\section{Surgical Procedure}

All surgical procedures were performed through midline sternotomy under normothermic cardiopulmonary bypass with intermittent antegrade warm blood cardioplegia. Patients with an indication for revascularization underwent coronary artery bypass grafting first. Subsequently, the mitral valve was exposed through a vertical transseptal approach along the right border of the foramen ovale, leaving the left atrial roof untouched. In patients with structural mitral valve disease, MVP was performed after thorough intraoperative visual and echocardiographic valve analysis according to standard Carpentier techniques. ${ }^{15}$ In patients in whom the mitral valve was deemed irreparable, MVR was performed. Mitral annuloplasty ring size was determined after careful measurement of the height of the anterior leaflet; in patients with functional MR, downsizing by 2 sizes (ie, size 26 when measuring 30) of a complete semirigid annuloplasty ring (Carpentier-Edwards Physio Ring; Edwards Lifesciences, Irvine, Calif) was routinely performed. In patients with severe degenerative aortic valve disease, aortic prosthetic valve replacement was performed if indicated. TVP was subsequently performed, also on normothermic cardiopulmonary bypass with intermittent antegrade warm blood cardioplegia, with a Carpentier-Edwards MC3 ring (Edwards Lifesciences) using the surface of the anterior leaflet as a reference. In patients with severe tricuspid valve leaflet tethering (ie, $\geq 8$-mm tethering distance), an additional pericardial patch augmentation of the anterior leaflet was performed to increase tricuspid leaflet coaptation. ${ }^{16}$ The restored leaflet coaptation was confirmed at the time of surgery by filling the RV and/or LV with saline through a bulb syringe and by visually inspecting the leaflets. Additionally, after weaning from cardiopulmonary bypass, intraoperative transesophageal echocardiography was used to assess the result of the valve reconstructions.

\section{Transthoracic Echocardiography}

Comprehensive 2-dimensional echocardiography examinations were performed with a commercially available system (IE33; Philips Medical Systems, Andover, Mass). Standard 2-dimensional and Doppler echocardiographic images were acquired in the left lateral decubitus position using a phased-array transducer in the parasternal and apical views by experienced cardiac sonographers. Three consecutive cardiac cycles were recorded and stored for subsequent offline analysis. LV end-diastolic and end-systolic dimensions were measured from parasternal acquisitions. LV volumes and ejection fraction were calculated using Simpson's biplane method according to the guidelines of the American Society of Echocardiography. ${ }^{17}$ Left and right atrial areas were measured by planimetry at end-systole from the apical 4-chamber views. Left atrial volumes were measured by Simpson's biplane method. Color flow was applied in the apical 4-chamber view to assess severity of TR, which was graded semiquantitatively on a scale from 0 to 4 as follows: 0 , none or trace; $1+$, jet area/atrial area $<10 \%$ (mild TR); $2+$, jet area/atrial area $10 \%$ to $20 \%$ (moderate TR); $3+$, jet area/atrial area $20 \%$ to $33 \%$ (moderate-to-severe TR); and $4+$, jet area/atrial area $>33 \%$ (severe TR). ${ }^{14,18}$ From the apical 4-chamber view, the RV end-systolic and end-diastolic areas were measured by planimetry with the transducer positioned to maximize the $\mathrm{RV}$ area and to include the RV apex. RV fractional area change (RVFAC) was used to determine RV systolic function and was calculated by the following formula: $\mathrm{FAC}=([$ diastolic area - systolic area $] /$ diastolic area) $\times 100 \% .{ }^{19} \mathrm{RV}$ long-axis length and RV short-axis width at the midventricular level were measured as described by Matsunaga and Duran ${ }^{20}$ and used to calculate the end-diastolic RV sphericity index as previously described (RVSI $=$ RV long-axis length/RV short-axis width) ${ }^{21}$ Systolic pulmonary artery pressure was measured by echocardiography using the modified Bernoulli equation on the transtricuspid continuous-wave Doppler signal, while adding right atrial pressure. In a minority of patients with no transtricuspid Doppler signal on preoperative echocardiography, systolic pulmonary artery pressure was adapted from preoperative right heart catheterization.

\section{Statistical Analysis}

Results are expressed as mean \pm standard deviation for continuous variables and as percentages for categorical variables. Continuous variables were compared using the 2-tailed Student $t$ test or the Wilcoxon signed rank test when the normality test failed. Categorical values were compared using the Fisher exact test. Interobserver and intraobserver agreement for RVFAC and RVSI measurement was tested by Bland-Altman analysis. Statistical analyses were performed using the Statistical Package for Social Sciences release 20.0 (SPSS, Inc, Chicago, Ill). We had full access to the data and take responsibility for its integrity. All of us have read and agreed to the manuscript as written.

\section{RESULTS \\ Patient Characteristics}

Baseline characteristics of the patients are summarized in Table 1. Mitral valve disease was the primary indication for cardiac surgery in both groups: $40(89 \%)$ patients and 27 $(82 \%)$ patients underwent MVP in the TVP and control groups, respectively, whereas $5(11 \%)$ patients and 6 (18\%) patients needed MVR in both groups, respectively. In the TVP group, $29 \%$ of TVP procedures were performed because of more than moderate $(>2+)$ preoperative functional tricuspid insufficiency and $71 \%$ because of TAD 


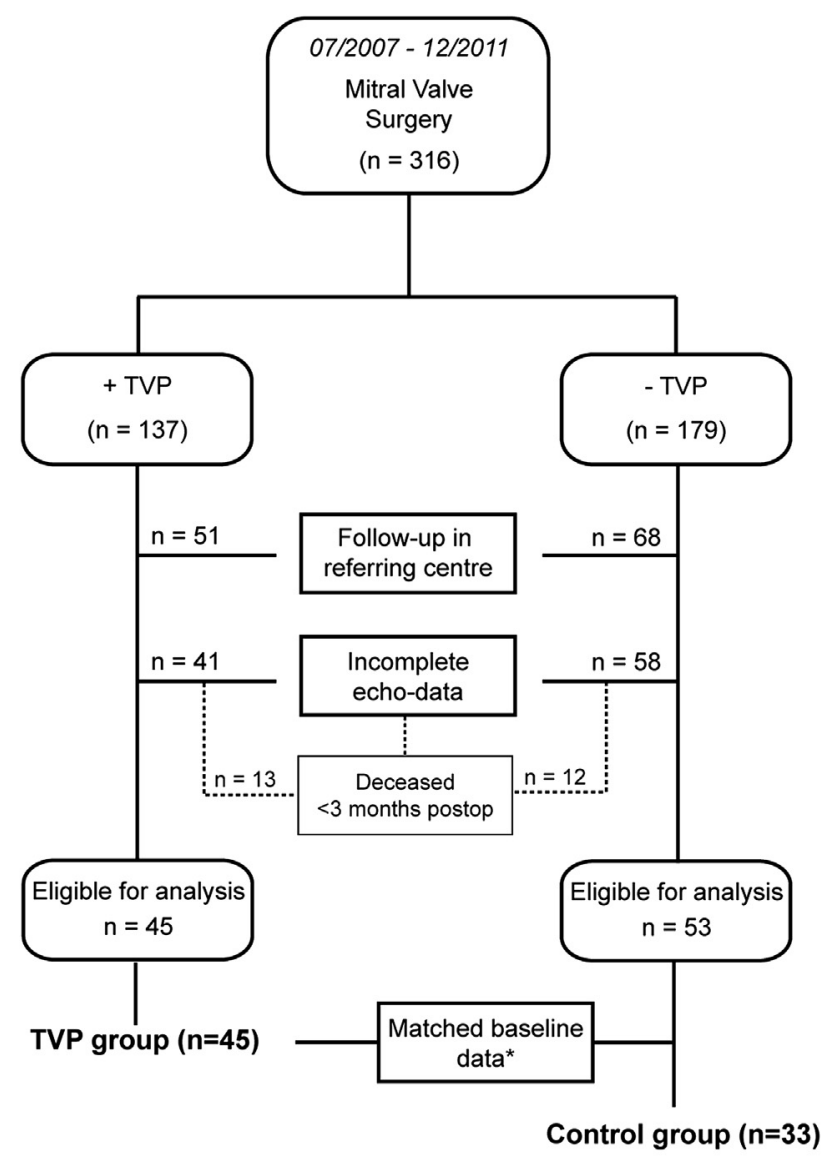

*Propensity-matched for baseline age, gender distribution, LV ejection fraction, LV end diastolic volume, and cardiopulmonary bypass time

FIGURE 1. Study flow chart. $R V$, Right ventricular; $T V P$, tricuspid valve annuloplasty; $L V$, left ventricular.

$\left(>40 \mathrm{~mm}\right.$ or $\left.21 \mathrm{~mm} / \mathrm{m}^{2}\right)$ in the absence of significant $(\leq 2+)$ TR. Pericardial patch augmentation of the anterior leaflet was performed in $2(4 \%)$ TVP patients. There was a significant difference in baseline right and left atrial dimensions between the 2 groups, likely explaining a higher incidence of atrial fibrillation in TVP patients, accounting for a relatively higher rate of maze procedures in this group and a difference in baseline anticoagulation therapy. Valvular repair was successful with residual MR/TR $\leq 1+$ in all patients as noted by periprocedural transesophageal echocardiography. Mortality at 3 months in the 197 patients with follow-up at our center was $15.1 \%(13 / 86)$ in the TVP group and $10.8 \%$ $(12 / 111)$ in the control group.

\section{Echocardiographic Remodeling}

Preoperative and postoperative echocardiography data are shown in Table 2. Postoperative data were obtained after a mean follow-up of $4.9 \pm 3.0$ months in the TVP group and $4.5 \pm 2.6$ months in the control group. A favorable change in RV geometry was observed in the TVP group as RVSI increased from $1.99 \pm 0.33$ to $2.21 \pm 0.42(P<.001$, Figure 2); that is, the RV became significantly less spherical. The opposite was observed in the control group, where the RVSI decreased from $2.34 \pm 0.52$ to $2.17 \pm 0.13$ $(P=.05)$ after mitral valve surgery. Indexed RV enddiastolic area increased significantly in the control group after surgery (from $10.3 \pm 1.9$ to $11.7 \pm 2.6 \mathrm{~cm}^{2} / \mathrm{m}^{2}$; $P=.003$ ) but remained unchanged in the TVP group (from $12.0 \pm 3.5$ to $11.8 \pm 3.6 \mathrm{~cm}^{2} / \mathrm{m}^{2}, P=.7$ ). Furthermore, there was a nonsignificant decrease in RV contractile function, as measured by RVFAC, after surgery in both groups (from $40.9 \% \pm 12.1 \%$ to $37.5 \% \pm 14.0 \%$ in TVP patients and from $44.2 \% \pm 11.1 \%$ to $40.6 \% \pm$ $10.2 \%$ in control patients; $P=.1$ and $P=.08$, respectively). TR grade decreased significantly in the TVP group after surgery (from $2.0 \pm 1.1$ to $0.5 \pm 0.7 ; P<.001$ ), whereas a slight but significant increase in TR was noted in the control group at follow-up (from $0.5 \pm 0.7$ to $1.2 \pm 1.1$; $P=.001$ ), as depicted in Table 2. In control patients, indexed tricuspid annular dimensions increased significantly (from $1.91 \pm 0.39 \mathrm{~cm} / \mathrm{m}^{2}$ to $2.08 \pm 0.33 \mathrm{~cm} / \mathrm{m}^{2}$; $P=.003)$, with progression toward more than moderate TR in $4(12 \%)$ patients. LV dimensions and function remained overall unchanged in both groups.

When RV geometry and function after surgery in TVP patients were compared with more than moderate TR $(n=13)$ versus TAD without significant TR $(n=32)$, a significant increase in RVSI was noted in both groups (from $1.90 \pm 0.33$ to $2.13 \pm 0.41$, and from $2.02 \pm 0.32$ to 2.24 $\pm 0.43 ; P=.04$ and $P=.007$, respectively) (Table 3). Furthermore, there was a significant decrease in RV enddiastolic area only in the group with more than moderate TR (Figure 2). RVFAC declined significantly in patients with more severe TR at baseline, whereas it remained relatively unchanged in those undergoing TVP because of TAD (from $42.5 \% \pm 8.8 \%$ to $35.6 \% \pm 6.9 \%$ and from $40.2 \% \pm$ $13.3 \%$ to $38.3 \% \pm 9.6 \% ; P=.02$ and $P=.5$, respectively).

\section{Determinants of Postoperative RV Size and Function}

In both patient groups, substantial variance in the difference between preoperative and postoperative RVFAC and $\mathrm{RV}$ end-diastolic area could be observed (Figure 3). To find possible determinants of these postoperative changes, we performed a univariable logistic regression analysis on the entire study population (TVP and control patients), after dichotomization into presence/absence of $>5 \%$ postoperative increase in RV end-diastolic area and $>10 \%$ decrease in RVFAC, that is, dichotomization at the level of the median. Among the many variables evaluated in the regression analysis were age at operation, cardiopulmonary bypass time, aortic clamp time, baseline medication, medical history, preoperative systolic pulmonary artery pressure, baseline RVFAC, RVSI, and RV end-diastolic area. This analysis, however, yielded no statistically significant 
TABLE 1. Baseline population characteristics

\begin{tabular}{|c|c|c|c|}
\hline Variables & TVP group $(n=45)$ & Control group $(n=33)$ & $P$ value \\
\hline Age, y & $68 \pm 11$ & $69 \pm 8$ & .8 \\
\hline Male gender & $17(52 \%)$ & $22(49 \%)$ & 1.0 \\
\hline Body surface area, $\mathrm{m}^{2}$ & $1.77 \pm 0.21$ & $1.77 \pm 0.20$ & .9 \\
\hline NYHA class & $2.67 \pm 0.76$ & $2.49 \pm 0.84$ & .3 \\
\hline \multicolumn{4}{|l|}{ Cardiovascular risk factors } \\
\hline Diabetes & $9(20 \%)$ & $9(27 \%)$ & .6 \\
\hline Hypertension & $24(53 \%)$ & $19(58 \%)$ & 1.0 \\
\hline Hyperlipidemia & $18(40 \%)$ & $17(52 \%)$ & .5 \\
\hline Obesity & $3(7 \%)$ & $5(15 \%)$ & .3 \\
\hline Smoking habits & $15(33 \%)$ & $15(45 \%)$ & .5 \\
\hline COPD & $8(18 \%)$ & $10(30 \%)$ & .28 \\
\hline CKD & $8(18 \%)$ & $4(12 \%)$ & .56 \\
\hline Familial history of ischemia & $10(22 \%)$ & $10(30 \%)$ & 6 \\
\hline \multicolumn{4}{|l|}{ Baseline medication } \\
\hline ACE-I/ARB & $20(44 \%)$ & $25(76 \%)$ & .01 \\
\hline Beta-blockers & $33(73 \%)$ & $24(73 \%)$ & 1.0 \\
\hline Loop diuretics & $26(58 \%)$ & $15(45 \%)$ & .4 \\
\hline Spironolactone & $12(27 \%)$ & $9(27 \%)$ & 1.0 \\
\hline Anticoagulation & $20(44 \%)$ & $6(18 \%)$ & .02 \\
\hline Antiplatelet therapy & $22(49 \%)$ & $28(85 \%)$ & .002 \\
\hline \multicolumn{4}{|l|}{ Echocardiography data } \\
\hline LV end-diastolic volume, $\mathrm{mL}$ & $123 \pm 52$ & $115 \pm 51$ & .5 \\
\hline LV end-systolic volume, mL & $65 \pm 45$ & $59 \pm 46$ & .5 \\
\hline LV ejection fraction, $\%$ & $51 \pm 16$ & $54 \pm 16$ & .3 \\
\hline $\mathrm{RV}$ end-diastolic area, $\mathrm{mm}^{2}$ & $21.8 \pm 5.8$ & $18.2 \pm 3.9$ & .002 \\
\hline Indexed RV end-diastolic area, $\mathrm{cm}^{2} / \mathrm{m}^{2}$ & $12.0 \pm 3.5$ & $10.3 \pm 1.9$ & .010 \\
\hline RVFAC, $\%$ & $40.9 \pm 12.1$ & $44.2 \pm 11.1$ & .2 \\
\hline RVSI & $1.99 \pm 0.33$ & $2.34 \pm 0.52$ & .001 \\
\hline TR grade & $2.0 \pm 1.1$ & $0.5 \pm 0.7$ & $<.001$ \\
\hline Tricuspid annular diameter, $\mathrm{cm}$ & $4.2 \pm 0.6$ & $3.4 \pm 0.6$ & $<.001$ \\
\hline Tricuspid annular diameter, indexed, $\mathrm{cm} / \mathrm{m}^{2}$ & $2.4 \pm 0.4$ & $1.9 \pm 0.4$ & $<.001$ \\
\hline $\mathrm{TR}<=2(\mathrm{n}=32 ; 71 \%)$ & $2.3 \pm 0.4$ & $1.9 \pm 0.4$ & $<.001$ \\
\hline TR $>2(\mathrm{n}=13 ; 29 \%)$ & $2.6 \pm 0.3$ & - & \\
\hline Right atrial area, $\mathrm{cm}^{2}$ & $20 \pm 7$ & $16 \pm 5$ & .005 \\
\hline Left atrial area, $\mathrm{cm}^{2}$ & $27 \pm 7$ & $22 \pm 5$ & .001 \\
\hline Systolic pulmonary artery pressure $(\mathrm{mm} \mathrm{Hg})$ & $47 \pm 15$ & $43 \pm 15$ & .4 \\
\hline \multicolumn{4}{|l|}{ Operative data } \\
\hline Cardiopulmonary bypass time, $\min$ & $219 \pm 68$ & $210 \pm 82$ & .6 \\
\hline Aortic crossclamp time, min & $164 \pm 43$ & $151 \pm 66$ & .4 \\
\hline Preoperative atrial fibrillation & $19(42 \%)$ & $5(15 \%)$ & .01 \\
\hline MVP & $40(89 \%)$ & $27(82 \%)$ & .3 \\
\hline MVR & $5(11 \%)$ & $6(18 \%)$ & .3 \\
\hline CABG & $20(44 \%)$ & $23(68 \%)$ & .04 \\
\hline AVR & $11(24 \%)$ & $6(18 \%)$ & 6 \\
\hline Modified maze procedure & $15(33 \%)$ & $3(9 \%)$ & .02 \\
\hline \multicolumn{4}{|l|}{ Etiology of mitral valve disease } \\
\hline Organic (Carpentier class II/IIIa) & $21(47 \%)$ & $19(58 \%)$ & .4 \\
\hline Rheumatic & $10(22 \%)$ & $8(24 \%)$ & 1.0 \\
\hline Degenerative & $11(24 \%)$ & $11(33 \%)$ & .45 \\
\hline Prolapse/flail & $5(11 \%)$ & $8(24 \%)$ & .14 \\
\hline Barlow disease & $2(4 \%)$ & $0(0 \%)$ & .5 \\
\hline Calcific disease & $2(4 \%)$ & $0(0 \%)$ & .5 \\
\hline Endocarditis & $2(4 \%)$ & $3(9 \%)$ & .65 \\
\hline Functional (Carpentier class I/IIIb) & $24(53 \%)$ & $14(42 \%)$ & .4 \\
\hline
\end{tabular}

TVP, Tricuspid valve annuloplasty; $N Y H A$, New York Heart Association; COPD, chronic obstructive pulmonary disease; $C K D$, chronic kidney disease; $A C E-I$, angiotensinconverting enzyme inhibitor; $A R B$, angiotensin receptor blocker; $L V$, left ventricular; $R V$, right ventricular; $R V F A C$, right ventricular fractional area change; $R V S I$, right ventricular sphericity index; $T R$, tricuspid regurgitation; $M V P$, mitral valvuloplasty; $M V R$, mitral valve replacement; $C A B G$, coronary artery bypass graft; $A V R$, aortic valve replacement. 
TABLE 2. Preoperative and postoperative echocardiography measurements

\begin{tabular}{|c|c|c|c|c|c|c|}
\hline \multirow[b]{2}{*}{ Variables } & \multicolumn{3}{|c|}{ TVP group $(n=45)$} & \multicolumn{3}{|c|}{ Control group $(\mathbf{n}=33)$} \\
\hline & Baseline & Follow-up & $P$ value & Baseline & Follow-up & $P$ value \\
\hline Mean follow-up, mo & & $4.9 \pm 3.0$ & & & $4.5 \pm 2.6$ & .5 \\
\hline $\mathrm{RV}$ end-diastolic area, $\mathrm{cm}^{2}$ & $21.8 \pm 5.8$ & $21.3 \pm 5.5$ & .6 & $18.2 \pm 3.9$ & $20.5 \pm 4.6$ & .002 \\
\hline Indexed RV end-diastolic area $\mathrm{cm}^{2} / \mathrm{m}^{2}$ & $12.0 \pm 3.5$ & $11.8 \pm 3.6$ & .7 & $10.3 \pm 1.9$ & $11.7 \pm 2.6$ & .003 \\
\hline $\mathrm{RV}$ fractional area change, $\%$ & $40.9 \pm 12.1$ & $37.5 \pm 14.0$ & .1 & $44.2 \pm 11.1$ & $40.6 \pm 10.2$ & .08 \\
\hline RV sphericity index & $1.99 \pm 0.33$ & $2.21 \pm 0.42$ & .001 & $2.34 \pm 0.52$ & $2.17 \pm 0.13$ & .05 \\
\hline TV annulus diameter, $\mathrm{cm}$ & $4,2 \pm 0.6$ & TVP & & $3.4 \pm 0.6$ & $3.7 \pm 0.5$ & .006 \\
\hline TV annulus diameter indexed, $\mathrm{cm} / \mathrm{m}^{2}$ & $2.4 \pm 0.4$ & TVP & & $1.9 \pm 0.4$ & $2.1 \pm 0.3$ & .003 \\
\hline TR grade & $2.0 \pm 1.1$ & $0.5 \pm 0.7$ & $<.001$ & $0.5 \pm 0.7$ & $1.2 \pm 1.2$ & .001 \\
\hline $\mathrm{TR} \leq 2, \mathrm{n}(\%)$ & $32(71 \%)$ & $44(98 \%)$ & & $33(94 \%)$ & $29(88 \%)$ & \\
\hline $\mathrm{TR}>2, \mathrm{n}(\%)$ & $13(29 \%)$ & $1(2 \%)$ & $<.001$ & $0(0 \%)$ & $4(12 \%)$ & .01 \\
\hline LV ejection fraction, $\%$ & $51 \pm 16$ & $50 \pm 16$ & .6 & $54 \pm 16$ & $54 \pm 15$ & .9 \\
\hline LV end-diastolic volume, $\mathrm{mL}$ & $123 \pm 52$ & $117 \pm 46$ & .5 & $115 \pm 51$ & $106 \pm 45$ & .3 \\
\hline Right atrial area, $\mathrm{cm}^{2}$ & $20 \pm 7$ & $14 \pm 4$ & $<.001$ & $16 \pm 5$ & $15 \pm 4$ & .5 \\
\hline Left atrial area, $\mathrm{cm}^{2}$ & $27 \pm 7$ & $23 \pm 6$ & $<.001$ & $22 \pm 5$ & $21 \pm 7$ & .5 \\
\hline Left atrial volume, $\mathrm{mL}$ & $97 \pm 33$ & $85 \pm 32$ & .01 & $71 \pm 25$ & $65 \pm 26$ & .2 \\
\hline Systolic pulmonary artery pressure, $\mathrm{mm} \mathrm{Hg}$ & $43 \pm 17$ & $37 \pm 9$ & $.2 *$ & $45 \pm 16$ & $36 \pm 12$ & $.008 *$ \\
\hline
\end{tabular}

Baseline pulmonary artery pressure data in this table represent the mean \pm standard deviation only for these 21 and 24 patients, respectively. TVP, Tricuspid valve annuloplasty; $R V$, right ventricular; $T V$, tricuspid valve; $T R$, tricuspid regurgitation; $L V$, left ventricular. *Paired samples: only $\mathrm{n}=21$ available in TVP group (owing to difficulty in measurement of echocardiographic TR signal after TVP), and $n=24$ in the control group.

predictor for postoperative increase in RV dimensions nor for decrease in RV function.

\section{Interobserver and Intraobserver Variability}

Preoperative and postoperative echocardiographic studies from 12 randomly selected patients were used to evaluate interobserver and intraobserver variability in the measurement of RVSI and RVFAC. The results showed good agreement for both measurements. The mean difference in RVFAC between different observers was 5.07\% $\pm 2.67 \%$; for the same observer, $3.51 \% \pm 1.43 \%$. The mean difference in RVSI between different and similar observers was $0.38 \pm 0.24$ and $0.22 \pm 0.19$, respectively.

\section{DISCUSSION}

The main finding of the current study is that performing TVP at the time of mitral valve surgery in patients with more than moderate TR or TAD without significant TR leads to favorable changes in RV geometry, with the RV becoming more elliptical and less spherical as illustrated by an increase in RVSI. These favorable changes did not occur in a propensity-matched control population. On the contrary, a significant increase in RV size and sphericity was observed after mitral valve surgery in these patients, along with progressive TAD and TR. Finally, the effects of TVP are different for patients with more than moderate preoperative TR compared with patients receiving "prophylactic TVP" because of TAD without significant TR. A significant decrease in RV size, but also in RV systolic function, was present only in the former subgroup.

Recent observations that TR does not always regress after successful mitral valve surgery and that occurrence of late
TR has an adverse impact on exercise capacity, reoperation rate, and outcome $\mathrm{i}^{1-3,22,23}$ have generally encouraged surgeons to routinely perform TVP at the time of mitral valve surgery when severe coexistent TR or tricuspid valve disease is present. In 2005, Dreyfus and associates ${ }^{6}$ reported on 311 patients undergoing MVP, showing that remodeling annuloplasty of the tricuspid valve should be based on the presence of TAD rather than the grade of TR. Accordingly, guidelines on the management of valvular heart diseases underwent further refinement, recommending correction also for $\mathrm{TR} \leq 2$ in case of significant TAD (diameter $>40 \mathrm{~mm}$ or $>21 \mathrm{~mm} / \mathrm{m}^{2}$ ). ${ }^{4,5}$ Our center, which is an experienced tertiary care and referral center, has strictly implemented these novel guidelines into daily clinical practice since 2007. Our current findings suggest that this strategy has beneficial effects on RV geometry and remodeling, that is, that TVP may induce "reshaping" of the RV and abolish the asymmetric and spherical dilation, which is most apparent at end-diastole, particularly in patients with significant preexisting TR. Restoring or preserving a normal RV shape and avoiding diastolic distortion of the interventricular septal geometry caused by RV volume overload may be an important factor to maintain or improve LV preload and ejection fraction. $^{24,25}$ Our results are in accordance with other recently published data, ${ }^{26,27}$ demonstrating that TVP performed concomitantly with MVP effectively inhibits ongoing RV dilation and associated postoperative TR.

Importantly, our study adds a couple of valuable nuances. Contrary to what might have been expected, concomitant tricuspid valve surgery did not lead to a reduction in RV size in the entire TVP population after 5 months of 


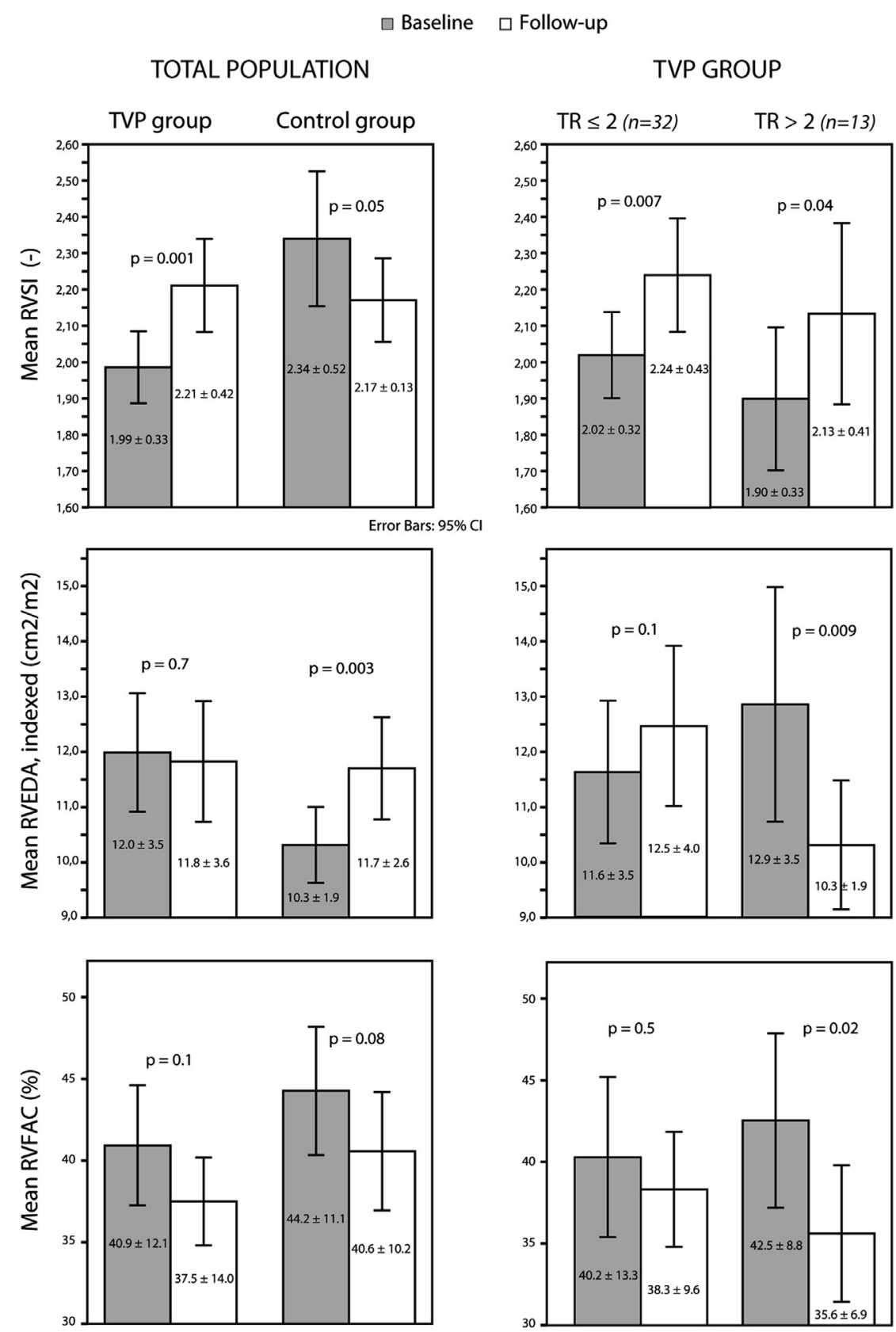

FIGURE 2. Echocardiographic indices of RV geometry and function at baseline and after 5 months of follow-up in the TVP and control group (left column), and subdivided within the TVP group according to the indication for TVP (right column). CI, Confidence interval; TVP, tricuspid valve annuloplasty; $T R$, tricuspid regurgitation; RVSI, right ventricular sphericity index; RVEDA, right ventricular end-diastolic area; RVFAC, right ventricular fractional area change.

follow-up. Only patients with more than moderate TR at baseline experienced a decrease in diastolic RV size after corrective tricuspid valve repair, comparable with what has been reported in previous studies on the hemodynamic effects of TVP in patients with severe TR. ${ }^{28,29}$ Therefore, our findings indicate a significant correlation between the preoperative severity of TR and the subsequent change in end-diastolic RV size, and support previous findings by Kim and coworkers, ${ }^{28}$ which showed that the extent of RV reverse remodeling after TVP is directly proportional to the extent of RV volume overload before surgery. In contrast, patients with TAD but only mild TR at baseline exhibited a small (albeit nonsignificant) increase in enddiastolic RV volume after surgery. Similarly, a decrease in $\mathrm{RV}$ function assessed by RVFAC was seen only in those with severe preexistent TR. This was anticipated, inasmuch as RVFAC is an ejection phase index that tends to overestimate ventricular contractile function in the presence of 
TABLE 3. Comparison of RV geometry and function within the TVP group

\begin{tabular}{|c|c|c|c|c|c|c|}
\hline \multirow[b]{2}{*}{ Variables } & \multicolumn{3}{|c|}{ Baseline TR $\leq 2(n=32 ; 71 \%)$} & \multicolumn{3}{|c|}{ Baseline TR $>2(n=13 ; 29 \%)$} \\
\hline & Baseline & Follow-up & $P$ value & Baseline & Follow-up & $P$ value \\
\hline $\mathrm{RV}$ end-diastolic area, $\mathrm{cm}^{2}$ & $21.4 \pm 5.6$ & $22.7 \pm 5.6$ & .2 & $22.6 \pm 6.6$ & $18.1 \pm 3.5$ & .01 \\
\hline Indexed RV end-diastolic area, $\mathrm{cm}^{2} / \mathrm{m}^{2}$ & $11.6 \pm 3.5$ & $12.5 \pm 4.0$ & .1 & $12.9 \pm 3.5$ & $10.3 \pm 1.9$ & .009 \\
\hline RVFAC, $\%$ & $40.2 \pm 13.3$ & $38.3 \pm 9.6$ & .5 & $42.5 \pm 8.8$ & $35.6 \pm 6.9$ & .02 \\
\hline RVSI & $2.02 \pm 0,32$ & $2.24 \pm 0.43$ & .007 & $1.90 \pm 0.33$ & $2.13 \pm 0.41$ & .04 \\
\hline
\end{tabular}

$R V$, Right ventricular; $T V P$, tricuspid valve annuloplasty; $T R$, tricuspid regurgitation; $R V F A C$, right ventricular fractional area change; $R V S I$, right ventricular sphericity index.

severe TR because of favorable loading conditions stemming from an increase in preload and decrease in afterload owing to the low impedance of the right atrium. Nevertheless, also in the subgroup of TVP patients receiving TVP because of TAD, as well as in the control population, substantial variance was found in postoperative change in RVFAC, with RV contractile force improving in some, but deteriorating in others. These findings lead us to believe that at least in some patients, perhaps more complex procedures (ie, combined mitral and aortic surgery or difficult/ time-consuming repair procedures) with prolonged aortic crossclamping times, are not well tolerated by the RV, despite adequate intermittent warm blood cardioplegia (in our patients intermittent cardioplegia of 3 minutes is applied every 15 minutes). These procedures might occasionally lead to postoperative adverse RV remodeling with ongoing RV dilation and significant deterioration of RV function despite correction of the left-sided lesion. Exactly in these patients, combining left-sided heart surgery with "prophylactic TVP" may prove beneficial at long-term follow-up and prevent de novo or gradually worsening TR. Our study lacked statistical power to discriminate distinct predictors of postoperative size and function, yet more information is clearly needed to explain why in some patients the RV is more vulnerable to ischemia/ reperfusion injury that is probably unavoidable during these prolonged procedures, despite routine implementation of protective strategies to prevent myocardial ischemia during cardioplegic heart arrest.

Once the left-sided lesion(s) have been addressed, a subsequent improvement in cardiac output may increase RV preload further and also lead to higher end-diastolic RV volumes, particularly in patients with lesser degrees of TR preoperatively. Indeed, increased preload and higher $\mathrm{RV}$ end-diastolic volumes may cause RV papillary muscle displacement and result in severe TR even in the absence of TAD, as shown recently. ${ }^{30}$ This subsequent rise in RV preload may be another important mechanistic cause of recurrent or progressive TR that is frequently observed late after mitral valve surgery and constitutes the rationale for our surgeons to consider TVP in patients scheduled for left-sided heart surgery when TAD is present, despite absence of significant TR.

Future well-powered studies implementing advanced imaging modalities and more sophisticated parameters of $\mathrm{RV}$ function are needed to address the complete impact of concomitant TVP on RV function and geometry, as well as to determine the impact of TVP on clinical outcome. These studies should also examine whether it is reasonable to lower the threshold for concomitant TVP even
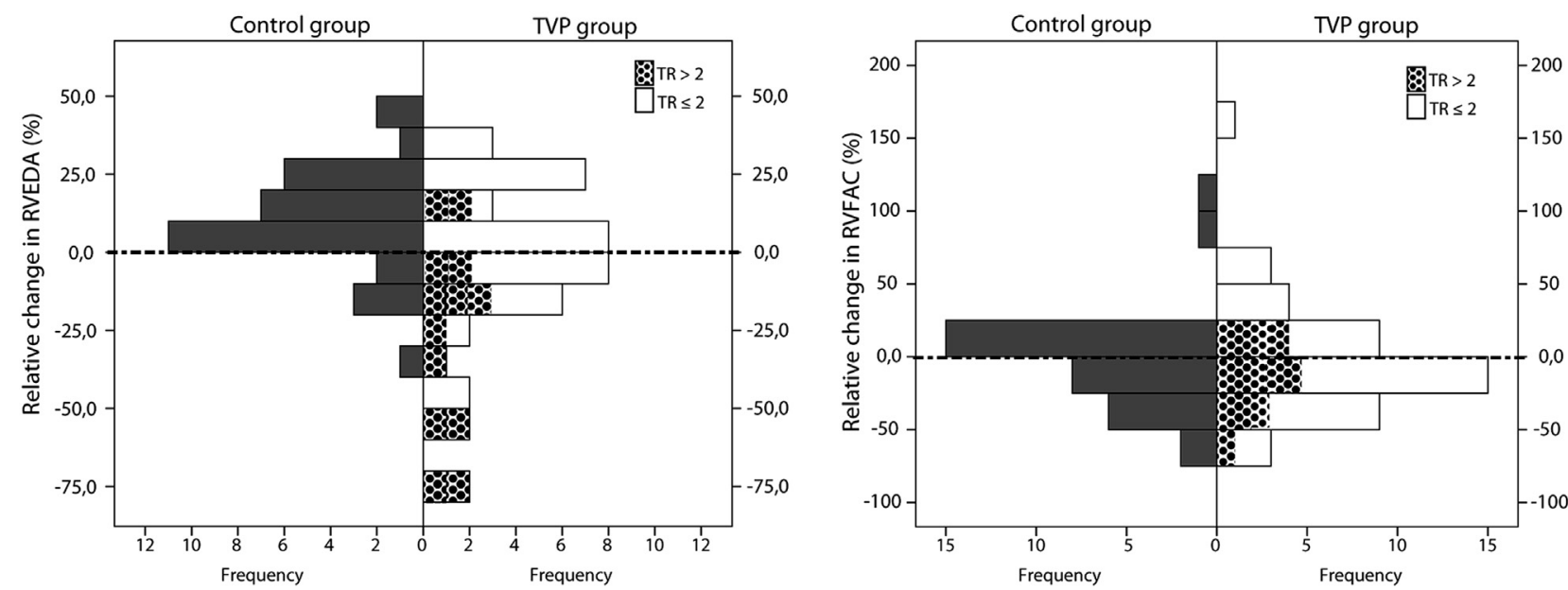

FIGURE 3. Relative postoperative changes in RVEDA and RVFAC in the TVP and control group. Within the TVP group, dotted areas indicate patients with baseline more than moderate TR, whereas monochromatic areas indicate patients with isolated TAD. RVEDA, Right ventricular end-diastolic area; $R V F A C$, right ventricular fractional area change; TVP, tricuspid valve annuloplasty; $T R$, tricuspid regurgitation; TAD, tricuspid annular dilation. 
further once the complexity of left-sided surgery or the anticipated aortic crossclamping time attains a certain level. Our center has therefore recently initiated a prospective randomized trial in patients with isolated TAD scheduled for left-sided heart surgery, with careful clinical followup and systematic dedicated imaging of the right ventricle at predefined time points (Clinicaltrials.gov identifier: NCT01580436).

\section{Study Limitations}

Obvious limitations inherent in the retrospective study design should be considered when these findings are interpreted. We acknowledge that follow-up duration was short in our study population and not enough to determine the long-term effects of TVP concomitant with mitral valve surgery. The sample size was small, with only $25 \%$ of all mitral valve procedures analyzed in this study. Furthermore, inasmuch as our mitral valve population comprised the whole spectrum of mitral valve disease instead of 1 type of mitral lesion, we were not able to differentiate the observed beneficial effect of TVP according to the different types of mitral valve disease. Previous studies have shown a potential benefit of TVP in patients with functional MR and rheumatic mitral valve diseases, whereas the effect of TVP in a degenerative prolapse population remains debated. ${ }^{23,31,32}$ In addition, our control population could not be matched to the TVP population with regard to RV function, geometry, and tricuspid annular dimension owing to the judicious implementation of the guidelines regarding concomitant TVP at our center. Finally, it may be argued that evaluation of RV function using 2-dimensional echocardiography is problematic because of the complex RV geometry and the sometimes limited definition of the endocardial surface caused by heavy trabeculation. However, analysis was performed on images acquired by experienced personnel, and care was taken to measure RVFAC (a parameter of RV function that is widely validated in many previous studies) from a true nonforeshortened apical 4-chamber view. Future studies with longer follow-up using more sophisticated parameters than RV end-diastolic area or RVFAC (eg, 3-dimensional echocardiography or cardiac magnetic resonance imaging for serial assessment of RV volume and systolic function) are needed to evaluate the exact effect of TVP on RV size or function.

\section{CONCLUSIONS}

Adding TVP to mitral valve surgery in patients with more than moderate TR or TAD without significant TR leads to favorable short-time changes in RV geometry and prevents ongoing postoperative RV dilation. These changes are most pronounced in patients with already more than moderate TR at baseline. Longer follow-up using more sophisticated parameters is necessary to evaluate the exact mechanisms by which TVP influences RV remodeling and to evaluate its effects on clinical outcome.

We thank Rozette Reyskens, RN, for her excellent support in the data collection and preparation of this manuscript. This study is part of the Limburg Clinical Research Program (LCRP) UHasselt-ZOL-Jessa, supported by the foundation Limburg Sterk Merk, Hasselt University, Ziekenhuis Oost-Limburg and Jessa Hospital.

\section{References}

1. Kwak JJ, Kim YJ, Kim MK, Kim HK, Park JS, Kim KH, et al. Development of tricuspid regurgitation late after left-sided valve surgery: a single-center experience with long-term echocardiographic examinations. Am Heart J. 2008; 155:732-7.

2. Tang GH, David TE, Singh SK, Maganti MD, Armstrong S, Borger MA. Tricuspid valve repair with an annuloplasty ring results in improved long-term outcomes. Circulation. 2006;114(1 Suppl):I577-81.

3. Song H, Kim MJ, Chung CH, Choo SJ, Song MG, Song JM, et al. Factors associated with development of late significant tricuspid regurgitation after successful left-sided valve surgery. Heart. 2009;95:931-6.

4. American College of Cardiology/American Heart Association Task Force on Practice Guidelines, Society of Cardiovascular Anesthesiologists, Society for Cardiovascular Angiography and Interventions, Society of Thoracic Surgeons, Bonow RO, Carabello BA, Kanu C, de Leon AC Jr, Faxon DP, Freed MD, et al. ACC/AHA 2006 guidelines for the management of patients with valvular heart disease: a report of the American College of Cardiology/American Heart Association Task Force on Practice Guidelines (writing committee to revise the 1998 Guidelines for the Management of Patients With Valvular Heart Disease) developed in collaboration with the Society of Cardiovascular Anesthesiologists: endorsed by the Society for Cardiovascular Angiography and Interventions and the Society of Thoracic Surgeons. Circulation. 2006;114:e84-231.

5. Vahanian A, Baumgartner H, Bax J, Butchart E, Dion R, Filippatos G, et al. Guidelines on the management of valvular heart disease: The Task Force on the Management of Valvular Heart Disease of the European Society of Cardiology. Eur Heart J. 2007;28:230-68.

6. Dreyfus GD, Corbi PJ, Chan KM, Bahrami T. Secondary tricuspid regurgitation or dilatation: which should be the criteria for surgical repair? Ann Thorac Surg. 2005;79:127-32.

7. Bax JJ, Braun J, Somer ST, Klautz R, Holman ER, Versteegh MI, et al. Restrictive annuloplasty and coronary revascularization in ischemic mitral regurgitation results in reverse left ventricular remodeling. Circulation. 2004;110(11 Suppl 1): II103-8.

8. Geidel S, Lass M, Schneider C, Groth G, Boczor S, Kuck KH, et al. Downsizing of the mitral valve and coronary revascularization in severe ischemic mitral regurgitation results in reverse left ventricular and left atrial remodeling. Eur $J$ Cardiothorac Surg. 2005;27:1011-6.

9. Kainuma S, Taniguchi K, Toda K, Funatsu T, Kondoh H, Nishino M, et al. Restrictive mitral annuloplasty for functional mitral regurgitation: acute hemodynamics and serial echocardiography. Circ J. 2011;75:571-9.

10. Gelsomino S, Lorusso R, De Cicco G, Capecchi I, Rostagno C, Caciolli S, et al Five-year echocardiographic results of combined undersized mitral ring annuloplasty and coronary artery bypass grafting for chronic ischaemic mitral regurgitation. Eur Heart J. 2008;29:231-40.

11. Romano MA, Bolling SF. Update on mitral repair in dilated cardiomyopathy. $J$ Card Surg. 2004;19:396-400.

12. Maffessanti F, Caiani EG, Tamborini G, Muratori M, Sugeng L, Weinert L, et al Serial changes in left ventricular shape after early mitral valve repair. Am J Cardiol. 2010;106:836-42.

13. Kouris N, Ikonomidis I, Kontogianni D, Smith P, Nihoyannopoulos P. Mitral valve repair versus replacement for isolated non-ischemic mitral regurgitation in patients with preoperative left ventricular dysfunction. A long-term followup echocardiography study. Eur J Echocardiogr. 2005;6:435-42.

14. Chopra HK, Nanda NC, Fan P, Kapur KK, Goyal R, Daruwalla D, et al. Can twodimensional echocardiography and Doppler color flow mapping identify the need for tricuspid valve repair? J Am Coll Cardiol. 1989;14:1266-74.

15. Filsoufi F, Carpentier A. Principles of reconstructive surgery in degenerative mitral valve disease. Semin Thorac Cardiovasc Surg. 2007;19:103-10. 
16. Dreyfus GD, Raja SG, John Chan KM. Tricuspid leaflet augmentation to address severe tethering in functional tricuspid regurgitation. Eur J Cardiothorac Surg. 2008;34:908-10.

17. Schiller NB, Shah PM, Crawford M, DeMaria A, Devereux R, Feigenbaum H, et al. Recommendations for quantitation of the left ventricle by two-dimensional echocardiography. American Society of Echocardiography Committee on Standards, Subcommittee on Quantitation of Two-Dimensional Echocardiograms. J Am Soc Echocardiogr. 1989;2:358-67.

18. Miyatake K, Okamoto M, Kinoshita N, Ohta M, Kozuka T, Sakakibara H, et al. Evaluation of tricuspid regurgitation by pulsed Doppler and two-dimensional echocardiography. Circulation. 1982;66:777-84.

19. Kaul S, Tei C, Hopkins JM, Shah PM. Assessment of right ventricular function using two-dimensional echocardiography. Am Heart J. 1984;107:526-31.

20. Matsunaga A, Duran CM. Progression of tricuspid regurgitation after repaired functional ischemic mitral regurgitation. Circulation. 2005;112(9 Suppl):I453-7.

21. Kim HK, Kim YJ, Park JS, Kim KH, Kim KB, Ahn H, et al. Determinants of the severity of functional tricuspid regurgitation. Am J Cardiol. 2006;98:236-42.

22. Groves PH, Lewis NP, Ikram S, Maire R, Hall RJ. Reduced exercise capacity in patients with tricuspid regurgitation after successful mitral valve replacement for rheumatic mitral valve disease. Br Heart J. 1991;66:295-301.

23. Bernal JM, Ponton A, Diaz B, Llorca J, Garcia I, Sarralde JA, et al. Combined mitral and tricuspid valve repair in rheumatic valve disease: fewer reoperations with prosthetic ring annuloplasty. Circulation. 2010;121:1934-40.

24. Lin SS, Reynertson SI, Louie EK, Levitsky S. Right ventricular volume overload results in depression of left ventricular ejection fraction. Implications for the surgical management of tricuspid valve disease. Circulation. 1994;90(5 Pt 2):II209-13.
25. Louie EK, Lin SS, Reynertson SI, Brundage BH, Levitsky S, Rich S. Pressure and volume loading of the right ventricle have opposite effects on left ventricular ejection fraction. Circulation. 1995;92:819-24.

26. Van de Veire NR, Braun J, Delgado V, Versteegh MI, Dion RA, Klautz RJ, et al. Tricuspid annuloplasty prevents right ventricular dilatation and progression of tricuspid regurgitation in patients with tricuspid annular dilatation undergoing mitral valve repair. J Thorac Cardiovasc Surg. 2011;141:1431-9.

27. Benedetto U, Melina G, Angeloni E, Refice S, Roscitano A, Comito C, et al. Prophylactic tricuspid annuloplasty in patients with dilated tricuspid annulus undergoing mitral valve surgery. J Thorac Cardiovasc Surg. 2012;143:632-8.

28. Kim HK, Kim YJ, Park EA, Bae JS, Lee W, Kim KH, et al. Assessment of haemodynamic effects of surgical correction for severe functional tricuspid regurgitation: cardiac magnetic resonance imaging study. Eur Heart J. 2010;31:1520-8.

29. Kim YJ, Kwon DA, Kim HK, Park JS, Hahn S, Kim KH, et al. Determinants of surgical outcome in patients with isolated tricuspid regurgitation. Circulation. 2009; $120: 1672-8$.

30. Spinner EM, Shannon P, Buice D, Jimenez JH, Veledar E, Del Nido PJ, et al. In vitro characterization of the mechanisms responsible for functional tricuspid regurgitation. Circulation. 2011;124:920-9.

31. Yilmaz O, Suri RM, Dearani JA, Sundt TM 3rd, Daly RC, Burkhart HM, et al. Functional tricuspid regurgitation at the time of mitral valve repair for degenerative leaflet prolapse: the case for a selective approach. J Thorac Cardiovasc Surg. 2011;142:608-13.

32. Izumi C, Iga K, Konishi T. Progression of isolated tricuspid regurgitation late after mitral valve surgery for rheumatic mitral valve disease. J Heart Valve Dis. 2002;11:353-6. 